\title{
AGE OF DISRUPTIVE INNOVATION THROUGH DIGITAL TECHNOLOGIES IN INDIA: ISSUES, CHALLENGES AND OPPORTUNITIES
}

\author{
Dr. M. A. SIKANDAR \\ Maulana Azad National Urdu University, Hyderabad, Telangana, India \\ Adjunct Faculty, Periyar Management and Computer College, GGS IP University, New Delhi, India
}

The next generation smart business essentially covers all such disruptive innovation in business to challenge the giant business organizations in every field. This disruptive innovation also refers to a futuristic exploitation of business opportunities by a business firm with a set of practices in conformity with the ethical and environmental standards set in a global context. The disruptive innovation through digital technologies has created a direct impact on the employment opportunity in the country and disrupted the world of work. There is a need to identify the issues, challenges and opportunities associated with these innovations and make remedial measures by the Industry and the Governments. These innovations have already blurred lines between employer and employee and brought a considerable challenge to the Government at large. This paper discusses about the issues, challenges and opportunities associated with such disruptive business practices through digital technologies and its possible impact on the industry, the employees, society and the economy at large. This paper also discusses about tackling the issues and concerns with a special reference to the Indian business environment.

KEYWORDS: Disruptive Innovation, Digital Technologies, Starts-up, Crowd-based Technologies, Automation \& Artificial Intelligence
\end{abstract}

Received: Apr 19, 2019; Accepted: May 10, 2019; Published: Jun 06, 2019; Paper Id.: IJHRMRJUN201921

\section{INTRODUCTION}

Disruptive Innovation, a term of art coined by Clayton Christensen, describes a process by which a product or service takes roots initially in a simple application at the bottom of a market and then relentlessly moves up market, eventually displacing established companies. Clayton further describes that such a smaller entity with fewer resources is also to successfully challenge established players and displace incumbent business by addressing a specific need that had hitherto not been addressed. The Clayton concept of disruptive innovation is about competitive responses and it is not a theory of growth. It is adjacent to growth but it is not about growth. The next generation smart business essentially covers all such disruptive innovation in business to challenge the giant business organizations in every field. Unless these giant business organizations engage themselves sufficiently, their very existences would be challenged by such disruptive business practices by small players with little resources but with their innovative ideas either to capture the markets or to make redundant a popular product produced by established business firms. According to Christensen, smart companies fail because they do everything right. They cater the high value customers and ignore the bottom of the pyramid of the market, where such disruptive innovations emerge from. 


\section{Innovative Business Practices}

According to Christensen, not because established companies do not innovate but because they are focusing on making good products in a better way for their existing customer base. This is called 'sustaining innovation' and it is completely different from disruptive innovation. The disruptive companies are usually exploit technologies to deliver new or existing products in radically different ways. For example Netflix moved away from its old business model of posting rental DVDs to customers to streaming on-demand video. In the case of Uber, it has moved up from the low end of the market. It targets customers who already use cabs. Disrupters start by appealing to low-end or un-served consumers and they migrate to the mainstream market. What Uber did was exactly opposite in which it built a position in the mainstream market segment first and subsequently appealing to the overlooked customer segments. Therefore, companies need to react to disruption but at the same time they should not overreact by dismantling a still-profitable business in the name of disruption.

Today in a highly volatile business environment, it is imperative on the part of business organisations to understand the vulnerability and the competitive dynamics of technology in which they operates. They should enable themselves to identify future threats and internal opportunities and discover how to direct those opportunities to meet strategic needs. There is a need for them to understand how changes in technology, regulatory environment in their field of territory and consumer preferences would lead to new opportunities for them as well as the new entrants. They should attempt to create strategic opportunities that outpace possible competition through such disruptive innovations to continue with their business with adequate market share. The top executives of the corporate have to engage themselves in the process of innovation to sustain the market. Exceptional business opportunities do not just happen but to create or they are to be made with continuous efforts. Sustaining innovation makes both products that can be sold for better profits to the best customers. When a business organization improves its products and satisfies the customer needs, it would ultimately helps to gain its market share.

\section{Innovation is Contagious: The Meteoric Rise of Samsung Brand}

Generally, when people talk about South Korea, only Samsung comes to their mind. Today, the Samsung Galaxy phone and other electronic products invaded every home be it Europe, America or India everywhere across the globe. The Samsung Group is a South Korea-based conglomerate company that includes a number of subsidiaries. It is one of the largest businesses in South Korea, producing nearly one fifth of the country's total exports with a primarily focus in the electronics, heavy industry, construction, and defence industries. From its humble beginnings in 1938 with just 40 employees with only 30,000 won (about \$27 USD) started a grocery store, Samsung is now about \$250 billion in revenues with about half a million employees today. Samsung is over Rs.50,000 crore business in India and established itself as the country's largest pure-play consumer goods MNC. Samsung has adopted the 'Make in India' initiative of the Government of India through which most of the products were designed and developed with the Indian consumer's needs in mind, has been a huge success and a big factor behind its growth. Today, Samsung makes everything from washing machines and refrigerators to smart phones and smart TVs. By launching a continuous stream of innovations, it is widely recognized as an industry leader in technology and ranks as a top-ten global brand. These innovations have not only propelled Samsung to global dominance but have also had a significant impact on the South Korean economy today. Innovation is contagious, and it often feeds other innovations. 


\section{Digital Technologies, Automation and Artificial Intelligence (AI)}

The top 50 companies on Boston Consulting Group ( $\underline{B C G)}$ 's most innovative Companies list-2019 today extensively use Artificial Intelligence (AI) platforms and eco-systems to enable themselves and other to pursue new products, services and ways of working. For example, McDonald uses an AI algorithm to serve digital menus that continuously change in response to such factors as time of day, day of the week, restaurant traffic, and weather. According to BCG's survey 2019, most companies are at least exploring the use of AI, and strong innovators are seeing positive results. Nine out of ten respondents in the survey responded that their companies were investing in AI and more than $30 \%$ expect AI to have the greatest impact over the next three to five years. The Survey concludes that the tools and technologies of innovation evolve. The basic orientation toward change-never being satisfied and always being willing to reinvent oneself-remains of some of the top ranked companies' lifeblood.

\section{Table 1: Most Innovative Companies 2019 by BCG's Survey}

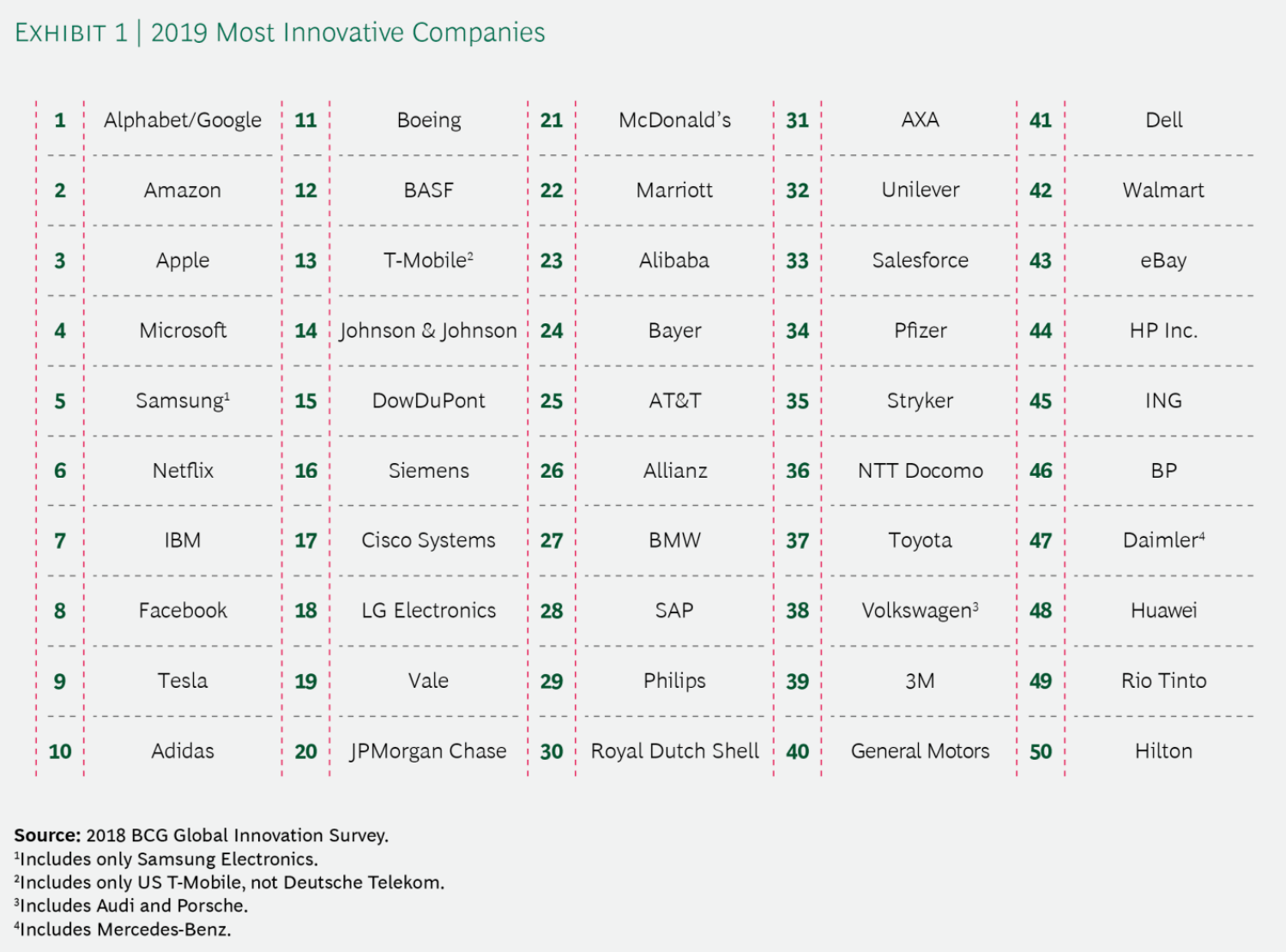

India is a living example of disruptive innovation through crowd-based technologies. India's prosperity is gemming from the the 'Startup' culture of Bangaluru and Hyderabad. Today the IT capital of India, Bangaluru and Hyderabad (Telangana) are the leader in technology and innovation exploiting the global market with the disruptive innovations. The advent of internet based technologies liberated the business environment from the erstwhile giant corporate houses in India. The internet provides the innovators a level playing field in the global arena. The business environment in via internet is still not regulated in corrupt ways and it is very prosperous for the Start-ups Firms. 


\section{Crowd-based Technologies and Its Impact on Employment Scenario}

The Crowd-based technologies form the basis of the so-called sharing economy, which resembles a mix of 'gift' and 'market' economies in its transactions. Sundarajrajn (2016) argues that these technologies, characterized by an array of on-demand platforms, are transforming a large number of industries, including transportations, hotels, banks and market places. Crowd based technologies have already created new occupations and sources of income generation for individuals and families in less developed countries. Airbnb, for example, has made it possible for an empty room in the home of an individual or household to become a source of income. Similarly, Uber, BlaBlacar and other crowd-based business are able to entice clients with their offer of relatively trustworthy and more affordable taxi and transportation services relative to regular taxi, bus or train services. As Sundarajan puts it, 'digital trust powers the sharing economy'. Technical advancement in automation and AI are complementary and mutually reinforcing. According to Sundrarajan, a sharing economy underpinned by crowd-based platforms through disruptive innovations mode reflects a new way of organizing economic activities, workers and consumers. That such crowd-based economy models raise serious issues regarding social protection of workers engaged in such economic activities.

\section{Disruptive Innovation and Its Impact on the Work Force}

The social media platforms through digital technologies are increasingly used to produce targeted advertisements, manipulate human emotion, and spread misinformation and even hatred. This is more so during elections in Indian context. While the AI, digital technologies can vastly improve the decision-making systems, improve efficiency and access to public services, they also run the risk of reinforcing existing biases and forms of exclusion. The mass volume of data generated through online platforms provides increasingly important inputs into the process of improving machine learning and AI; data are also a critical determinant of the market power of large technology based companies. The world of work is bound to change because of the innovation and technology intervention in business and services. The Artificial Intelligence is a big challenger to growing economies like India where a large population of young and educated youths searching for jobs after coming out from thousands of Engineering Institutions and Business Schools. According to the latest Survey by Mercer's 2019 Global Talent Trends Study, 88\% of Executives in India predicts significant disruptions around their jobs as compared with $40 \%$ in $2018.76 \%$ of Companies in India plan to automate more work in the next 12 months. $62 \%$ of HR leaders in India are involved in planning the rollout of major change project. Two in three employees concerned that Artificial Intelligence (AI), automation will replace their job. 54\% of employees in India want curated learning to help them evolve their skills and prepare for future jobs which show the positive side of the trend to face the challenge by machines at work place. Mercer's study identifies four top trends that leading companies are pursing in 2019: Aligning Work to Future Value, Building Brand Resonance, Curating the Work Experience, and Delivering Talent-led-Change. The Table shows that Industries that expecting most disruptions: 


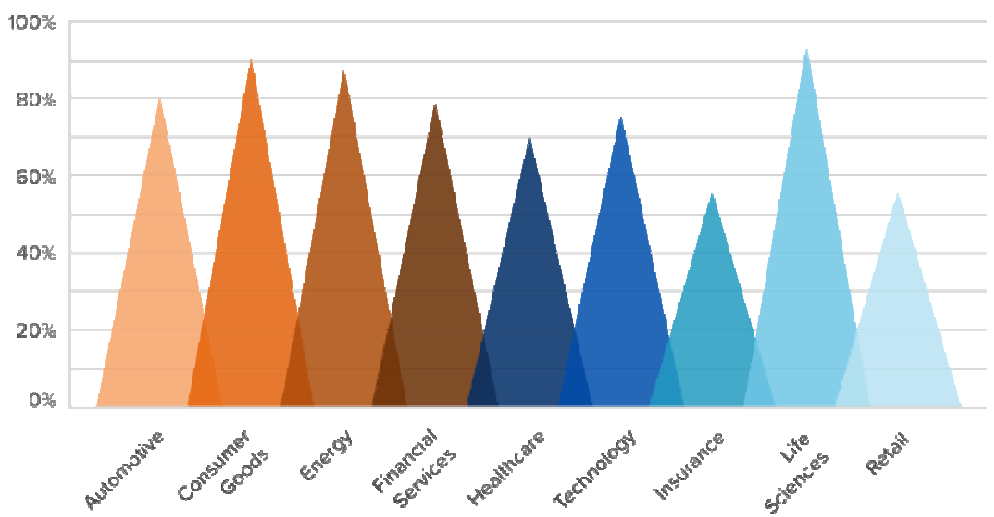

(Source: Mercer's 2019 Global Talent Trends Survey 2019)

Figure 2: Industries: Which Ones Expect the Most Disruption?

\section{CONCLUSIONS}

The line between employer and employee is blurred through these disruptive innovations through digital technologies across the globe. The new technologies have the potential to create new occupations, representing opportunities for decent employment, if appropriate policies are crafted by the Governments. Both sets of frontier technologies viz. Technical advancement in automation and AI promise of new prosperity with risks of unemployment, underemployment and inequality in the society. The actual and potential applications of AI in sectors such as manufacturing, transportation, language learning, health care and public administration can generate the kind of employment which would call for an increasingly more skilled workers. In fact, data coming from sensors, wearable and individuals are already feeding new activities and creating jobs in data collection, tabulation and analysis, which are useful for generating higher value added and improved efficiency in agriculture, manufacturing and public administration (Ghosh; McKinsey Global Institute, 2017b). But at the same time, automation can also have negative social and economic implication.

This is expected to bring more challenge to the Business Schools and Technical Institutes in India to cope up the changes brought out by such innovation in business. Such disruptive innovations through digital technology through startups can alone bring more job opportunities and to sustain the economy at this crucial juncture. The young corporate workforce should make themselves for future ready for such challenges at work place. Similarly, every business organization has to make efforts from idea to value creation and should be catalyst for organizational change and uncover the patterns that compose disruptive innovations.

\section{REFERENCES}

1. Christensen Clayton M., Raynor Michael E., and McDonald Rory, What is Disruptive Innovation? (2015); Harvard Business Review, December 2015 Issue.

2. Christensen Clayton M., Ojomo Efosa and Dillon Karen (2019), The Prosperity Pradox: How Innovation Can Lift Nations Out of Poverty, Harper Business

3. Ghosh, Jayati (2016). Ideas on the Future of Work. Presentation at a discussions Organized by the International Labour Organization on the Future of the Work and the Implication of Technology on Jobs. YouTube. 5 February 2016. Available at www.youtube.com 
4. Sundararajan, Arun (2016), The Sharing Economy: The End of Employment and the Rise of Crowd-based Capitalism, Cambridge: MIT Press

5. Berliandaldo, M., \& Hidayat, A. (2017). Implementing Talent Management Approach, to Improve Non-Tax Revenue in Center for Innovation. International Journal of Business and General Management (IJBGM), 6(6), 47-56.

6. World Economic and Social Survey, 2018 - Frontier Technologies for Sustainable Development, United Nations publications (E/2018/50/Rev.1

7. Kumar, R. (2017). Prospects of Sustainable Fashion Design Innovation. International Journal of Textile and Fashion Technology (IJTFT), 7(6), 5-14.

8. Mercer's Global Talent Trends Study (2019): Connectivity in the Human Age. https://www.mercer.co.in

9. The Most Innovative Companies 2019: The Rise of AI, Platforms and Ecosystems, Boston Consulting Group (March, 2019)

10. Article by Burris, Mathew, The History of Samsung (1938-Present), Lifewire, updated September 04, 2018.

11. Article by Mukerjee, Writankar, Samsung is a Rs. 50,000 crore business in India The Economic Times, June 01, 2018. 